\title{
Modernidade(s) educacional, cosmopolitismo e portugalidade em 105 anos da Deutsche Scule zu Porto
}

\author{
(Educational modernity, cosmopolitanism and portugueseness \\ for over 105 years at the Deutsche Scule zu Porto)
}

\author{
Francisco Miguel ARAÚJO \\ Faculdade de Letras da Universidade do Porto \\ CITCEM / IHC
}

\begin{abstract}
RESUMO: A Deutsche Schule zu Porto, fundada em 1901, destaca-se no panorama educativo português como uma das escolas estrangeiras mais antigas em funcionamento, apesar das muitas vicissitudes sofridas ao longo do século XX, intimamente articuladas com a evolução política e educativa entre o país de origem e 0 de acolhimento. Este estudo apresenta uma breve história institucional deste estabelecimento de ensino particular em diferentes momentos, incluindo uma breve passagem pela Galiza, sublinhando a modernidade e inovação dos seus modelos pedagógicos e finalidades educativas. Assim como o cosmopolitismo de um paradigma baseado num sistema educativo alemão em constante transfiguração, sem com isso jamais prescindir de uma aculturação à realidade portuguesa ainda hoje cultivada.

PALAVRAS-CHAVE: História da Educação; relações internacionais; ensino luso-alemão; educação integral; inovação pedagógica.

ABSTRACT: The Deutsche Schule zu Porto, founded in 1901, is one of the oldest functioning foreign schools in Portugal. During its more than a century-long existence, it has undergone many changes, in step with political and educational developments in both its homeland and its host country. This article offers a brief institutional history of the school at different times in its history, including a brief relocation to Galicia. The analysis highlights the modernity and innovation of its pedagogical models and educational goals, and sheds new light on the cosmopolitan paradigm born of its simultaneous responsiveness to developments within the German education system and its ongoing process of acculturation to life in Portugal.
\end{abstract}

KEYWORDS: History of Education; international affairs; Portuguese-German teaching; holistic education; pedagogical innovation. 


\section{Colégio Alemão do Porto na confluência entre a cidade e a comunidade luso-alemã (1901-2019)}

Quem conhece a cidade do Porto ou dela tem alguma perceção, nem que seja associada ao célebre vinho fino do Douro que se comercializa um pouco por todo o mundo, a presença de comunidades estrangeiras não surpreende pela variedade de sobrenomes internacionais que se podem encontrar em edifícios, lojas ou em painéis publicitários. Num burgo com uma matriz multisecular ligado às navegações marítimas e ao comércio internacional, o elemento estrangeiro converteu-se em traço indissociável na composição do seu tecido social, muito antes do atual fenómeno turístico que a tornou em destino da moda, aqui estabelecendo as suas residências, firmas e negócios desde finais da Idade Média. ${ }^{1}$

Na sequência da expansão marítima e do dinamismo do comércio dos vinhos do Alto Douro na era moderna, dois grandes corpos sociais sobressaíam entre os grupos de fora do reino. Os britânicos que se imiscuíram neste último setor económico, através da constituição de companhias produtoras e exportadoras de vinho do Porto; e os vizinhos espanhóis que se empregavam maioritariamente nas atividades marítimas como mestres, pilotos e marinheiros, mas também como trabalhadores braçais ou até proprietários de pequenos negócios na área da restauração e hospedaria:

Os galegos eram os mais frequentes. Se há lógicas de comportamentos, e contradições, a relação com os vizinhos era a mais estreita e, ao mesmo tempo, a mais difícil. Com ritmos económicos e produtos transaccionados idênticos, e com um mercado frágil e pouco flexível, as articulações e cooperação de hoje transformavam-se na concorrência e animosidade de amanhã. ${ }^{2}$

A colónia alemã só em finais de Oitocentos começará a ganhar maior projeção social no universo portuense ${ }^{3}$ mesmo tendo em conta a prévia existência de comunidades germânicas que nesta época se uniram sob a égide do Império Alemão (1871-1918), diversificando os seus interesses económicos do vinho do Porto para as emergentes indústrias de ponta - têxtil, metalúrgica, química, gráfica e outras - quer na condição de filiais representantes de marcas e empresas além-fronteiras, quer a título individual investindo na fundação de firmas comerciais e de unidades fabris.

Famílias como os Kopke, von Hafe, Biel, Stüve, Cudell, Burmester, Claus ou Schweder, entre outras tantas, despontaram nesta sociedade de acolhimento pelo seu estatuto socioeconómico e pelas redes de sociabilidade estabelecidas, bem menos herméticas do que outras similares nos contatos com a população nacional, como espelham as muitas notícias dos periódicos locais. Não obstante, a afirmação da identidade e do sentimento nacionalista face ao /l Reich suscitaram a perpetuação dos padrões culturais alemães,

\footnotetext{
${ }^{1}$ Vd. Luís de Oliveira Ramos, coord., História do Porto (Porto: Porto Editora, 2015).

${ }^{2}$ Amândio Barros, «Nas origens de uma respublica marítima e mercantil: 0 acolhimento ao estrangeiro nos portos medievais e modernos", CEM - CEM Cultura, Espaço \& Memória, no. 6 (2015): 45.

${ }^{3}$ Segundo os dados constantes nos Censos do século XIX para a população estrangeira residente na cidade do Porto, dominada pela tríade de espanhóis, brasileiros e ingleses, os alemães ocupavam o quinto lugar, logo a seguir aos franceses, entre 1890 (172 -2,99\%) e 1900 (167 -3,19\%). Direcção-Geral da Estatística, Censo da População de Portugal no 1. 을 Dezembro de 1911:V recenseamento geral da população (Lisboa: Imprensa Nacional, 1913), 354-355.
} 
alicerçado na fundação e patrocínio de instituições endógenas na cidade - o Club Alemão, a Igreja Evangélica Alemã e o Colégio Alemão - espaços de convívio social e cultural em que língua, religião e educação da pátria-mãe eram assegurados aos seus descendentes e aos demais curiosos de outras nacionalidades.

Nesta dualidade sociológica e educativa ao longo de mais de um século justificou-se a inclusão da Deutsche Schule zu Porto ou Colégio Alemão do Porto (C.A.P.), no âmbito do PROJETO INOVAR - Roteiros da inovação pedagógica: escolas e experiências de referência em Portugal no século $X X,{ }^{4}$ como uma instituição de relevante modernidade educativa e de inovação pedagógica. ${ }^{5}$ Um estabelecimento de ensino particular e cooperativo integrado na rede de escolas alemãs no estrangeiro, naturalmente cumprindo o respetivo programa educativo em total respeito pela sua autonomia administrativa e pedagógica, que celebrará em breve 105 anos de efetiva atividade na qualidade de uma das mais antigas de cariz internacional, tanto no quadro nacional como no ibérico. ${ }^{6}$

É certo que a sua vida institucional esteve longe de ser ininterrupta, a ligação supranacional ao Estado alemão por ocasião das duas guerras mundiais obrigou ao seu encerramento transitório, responsável também pelo extravio de parte do seu espólio documental. Mas, curiosamente, tanto as comunidades luso-alemã como a portuense demonstraram uma enérgica e proativa atitude na sua pronta reabertura em tempos de paz, instigando junto das entidades governativas de ambos os países no seu auxílio político e financeiro para um projeto pedagógico transversal às duas nações. Graças a tal, o C.A.P. tornou-se palco privilegiado de modernidade em território educativo, com diversos ensaios curriculares, didáticos e pedagógicos a serem implementados na sua forma escolar, alguns de um inegável pioneirismo rumo a uma educação integral e liberal.

Justamente, num tempo histórico longo envolvendo as vivências e missão educativa do C.A.P., serão algumas destas diretrizes inovadoras que 0 artigo pretende realçar e contextualizar nas suas especificidades e complementaridades, em comparação com as transmutações do próprio sistema educativo português. Princípios basilares como a educação bilingue e intercultural, as metodologias ativas e digitais ou a sólida formação sociocultural científica e artística que, pela equiparação entre graus académicos de um ciclo de estudos

\footnotetext{
${ }^{4}$ Projeto financiado pela Fundação para a Ciência e Tecnologia (PTDC/MHC-CED/0893/2014).

${ }^{5}$ Francisco Miguel Araújo, "O Colégio Alemão do Porto (1901-2001): um processo de inovação pedagógica a três tempos", em Roteiros da Inovação Pedagógica: Escolas e experiências de referência em Portugal no século XX I Itineraries of pedagogical innovation: reference schools and experiences in Portugal in the twentieth century, coord. Joaquim Pintassilgo \& Luís Alberto Marques Alves (Lisboa: Instituto de Educação da Universidade de Lisboa, 2019), 103-136. Com os devidos agradecimentos à direção do C.A.P. na prossecução do trabalho de investigação que se encontra na sua génese.

${ }^{6}$ Em Portugal, entre as mais antigas escolas estrangeiras fundadas até meados do século passado, ainda em funcionamento, surgem a Deutsche Schule Lissabon (1848), a Oporto British School (1894), a Deutsche Schule zu Porto (1901), o Lyceé Français Charles Lepierre (Lisboa, 1907), a St. Julian's School (Carcavelos, 1932) e o Colégio Luso-Francês (Porto, 1936). Relativamente às escolas alemãs fundadas em Espanha e Portugal, saliente-se a seguinte cronologia sinótica: Lisboa (1848), Barcelona (1894), Madrid (1896), Málaga (1898), Porto (1901), Santa Cruz de Tenerife e Valência (1909), Bilbao (1917), Las Palmas (1920), San Sebastian e Sevilha (1921) e a do Algarve (1996).
} 
completos do ensino pré-escolar ao secundário, conservam uma relevância e prestígio que atrai todos os anos um significativo público escolar multicultural e cosmopolita.

\section{Colégio Alemão do Porto: 1.ำ período (1901-1916)}

Antes da institucionalização do C.A.P. no raiar do século $\mathrm{XX}$, já a comunidade alemã revelara 0 seu interesse em garantir a educação dos elementos mais jovens, geralmente recorrendo ao ensino doméstico com a contratação de perceptores de raízes germânicas. Alguns destes logrando da crescente procura da instrução pública por famílias de outras nacionalidades, que a rede escolar pública não conseguia comportar pelo número restrito de estabelecimentos, acabariam por apostar na abertura de colégios privados na cidade. Exemplos como o Colégio Alemão de Berta Becks, o Colégio Inglês-Alemão de Mme. d'Espiney ou o Colégio Von Hafe publicitavam uma formação segundo os cânones internacionais, ainda que aparentemente mais centrada na aprendizagem das línguas vivas, comprometendo a sua oferta educativa aos conteúdos e programas curriculares exigidos para aprovação nos exames das classes dos magistérios primário e liceal nacionais. ${ }^{7}$

Plausivelmente, esta carência de uma verdadeira identidade nacional não seria assaz sedutora para que as famílias alemãs aí inscrevessem os seus filhos, pois, em 1900, estes elementos constituem a "Comunidade Evangélica e Escolar Alemã do Porto", apoiados pela sua congénere de Lisboa na figura do Pastor Boit. Movendo influências em favor desta colónia, a segunda maior em território português, a ele se deve a atribuição de um subsídio de três mil marcos anuais pela secretaria de Estado dos Negócios Estrangeiros do /I Reich para a fundação de uma Igreja Evangélica e de uma Escola, igualmente acrescido com os donativos particulares destes luso-alemães nortenhos que há muito as reclamavam.

O Pastor Martin Richter, antigo professor na Escola Alemã da Amora - Seixal, foi 0 escolhido para assumir esta empreitada, fixando-se no Porto, em outubro de 1901, em casa alugada da rua da Restauração, onde no dia 27 proferiu a primeira cerimónia religiosa da nova Capela Alemã. Finalmente, a 18 de novembro, inaugurava as atividades letivas do C.A.P. como seu primeiro diretor nesse mesmo edifício, recebendo 18 rapazes e 3 raparigas, todos eles exclusivamente de nacionalidade alemã. Inicialmente ministrou-se o ensino primário obrigatório em seis classes ${ }^{8}$ (Volksschule) nesse mesmo idioma, para 0 qual funcionou um curso especial para reforçar a fluência linguística dos alunos durante três anos; onde o Pastor Ritcher, um professor e dois auxiliares foram regendo as aulas de escrita, aritmética, alemão, desenho, história, geografia, ginástica, canto e religião protestante, decalcadas do modelo educativo formal em vigor na pátria de origem.

Quando estes alunos cumpriram com sucesso este ciclo de escolaridade colocou-se um dilema ao estabelecimento e às suas famílias, visto que para prosseguirem para o ensino liceal teriam de, forçosamente, requerer a transferência para uma escola portuguesa ou inclusive serem enviados para a Alemanha como pensionistas. Os administradores da

\footnotetext{
${ }^{7}$ Araújo, "O Colégio Alemão do Porto (1901-2001)", 108-110.

8 O termo "klasse" no desenho curricular alemão tem correspondência com o de "curso" e "ano de escolaridade" dos sistemas educativos espanhol e português, respetivamente.
} 
Comunidade Evangélica e Escolar, em 22 de janeiro de 1907, anuíram na contratação de mais um professor alemão para as disciplinas de matemática e de história natural, permitindo a abertura de duas novas classes e elevando a oferta educativa para os primeiros anos do ensino secundário (Realschule). Assim, era-lhes facilitada a inscrição como voluntários nos exames a efetuar nos liceus nacionais, de modo a obter as certidões ou diplomas académicos necessários para continuar estudos ou ingressar no mercado de trabalho.

Contudo, um dos anos mais vanguardistas e simbólicos em toda a história institucional do C.A.P. foi 0 de 1909, perante a exiguidade das verbas financeiras garantidas pelos organismos supranacionais, que eram partilhadas ainda com as despesas da Igreja Evangélica. Primeiro, na urgência de procurar novos sócios e fontes de financiamento entre o panorama citadino e da região norte, desvincularam-se as duas entidades, a religiosa e a escolar, para demarcar esta última num país católico sob a gestão da recém-criada "Associação Escolar do Colégio Alemão do Porto" (Schulverein der Deutschen Schule zu Porto). Depois da nomeação do Prof. Alexender Geys como seu diretor e a mudança de instalações para a rua do Breiner, a 29 de dezembro, a assembleia geral sancionou a admissão de alunos de outras nacionalidades, sub conditione de um preço mais elevado na propina anual e da obrigatoriedade do exame de admissão às classes mais avançadas.

Pela primeira vez, será contratado um professor português para lecionar a história e geografia de Portugal, correspondendo aos interesses da sociedade portuense com maior número de alunos matriculados, por oposição à presença mais tímida de crianças de origem brasileira, suíça, francesa, austríaca e norueguesa. No entanto, a todos era exigida a comunicação em língua alemã na sala de aula e no recreio, a assiduidade e disciplina exemplares e a frequência dos programas e o cumprimento do calendário escolar germânicos, em disparidade com 0 adotado na rede oficial pública por se iniciar em abril em vez do tradicional outubro.

\section{Gráfico 1. Frequência escolar do C.A.P. ao longo do seu $1 . \stackrel{0}{-}$ período ${ }^{9}$}

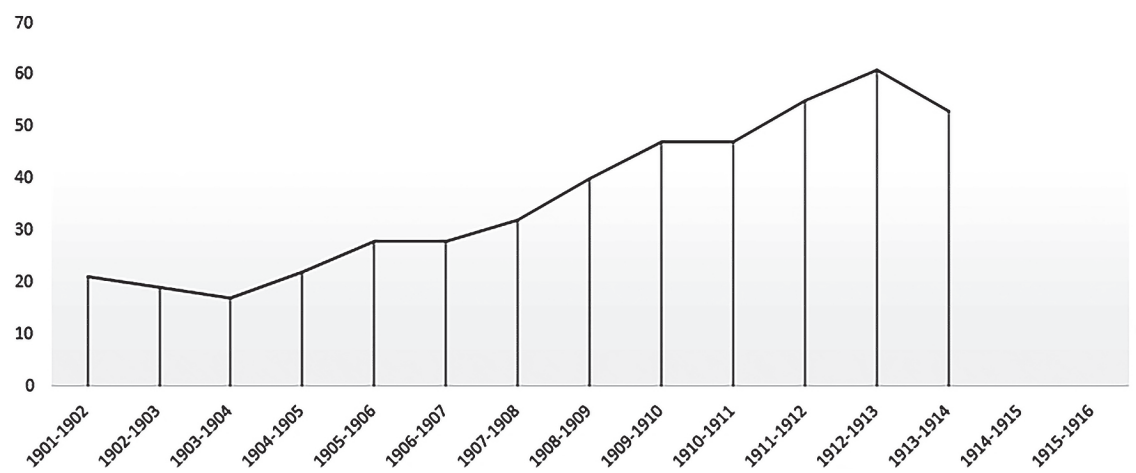

Fonte: Arquivo escolar da Deutsche Schule zu Porto.

\footnotetext{
${ }^{9}$ Na elaboração deste gráfico estatístico e dos seguintes, relativos à evolução do número de matrículas escolares, chama-se a atenção para duas situações: a ausência de valores para alguns dos anos letivos e da distinção por nacionalidades destes alunos, derivado da perda da documentação arquivística para a sua reconstituição total.
} 
A proclamação da $1 .^{a}$ República (1910-1926) pouco interfere neste cenário educativo, com as novas autoridades políticas a reconhecer plenamente o C.A.P. como estabelecimento de ensino estrangeiro particular, com personalidade jurídica constituída pela sua comissão de administração e financiamento externo provindo do Império Alemão, que reconhecera oficialmente o novo regime após a aprovação da Constituição de 1911. Em paralelo, o número de alunos continuava a aumentar, ao ponto de exigir nova mudança de instalações para edifício mais amplo na mesma rua, sinal de que o seu prestígio institucional e projeto educativo tinham conquistado as famílias lusas, que em pouco de mais de meia centena de alunos ocupavam já um terço do total e com uma notória tendência de crescimento anual. ${ }^{10}$

Uma análise do Regulamento Escolar e dos relatórios da Associação Escolar deste período refletem algumas orientações do modelo pedagógico adotadas: a primazia da língua alemã no processo de ensino-aprendizagem, a importância da educação artística e física e a valorização das atividades lúdicas, quer durante os intervalos e recreios, quer em passeios semanais para organização de coleções zoológicas e botânicas pelos alunos ou meros passeios de lazer pela área circundante. Ao contrário da maioria das escolas portuguesas, em que a pedagogia tradicional assente na memorização e repetição relegava os estudantes a uma postura mais passiva, os docentes do C.A.P. eram apologistas das conceções educativas de Pestalozzi e de Fröbel incentivando uma educação mais ativa e intuitiva, respeitando o tempo para a descoberta e consolidação individual dos conhecimentos e a limitação da estratégia de trabalhos para casa.

A eclosão mundial da Grande Guerra de 1914-1918 acabou por embaraçar a vida académica do C.A.P. pela intervenção beligerante do // Reich entre as Potências Centrais, não só pelo corte no financiamento estatal às suas escolas no estrangeiro, mas também pela mutação da perceção social da colónia alemã como um potencial rival da causa demoliberal dos Aliados, em que Portugal se revia pelas suas relações diplomáticas com 0 Reino Unido e a França. ${ }^{11}$ Seguindo a ordem de mobilização compulsiva para os cidadãos masculinos no Exército (Deutsches Heer), algumas destas famílias residentes no Porto decidiram-se por um exílio voluntário, antecipando-se à declaração formal de guerra entre as duas nações, a 9 de março de 1916. 0 que aliado ao galopar da inflação económica mundial, deixaram a Associação Escolar com pouquíssimos recursos para fazer face às despesas correntes.

Até à decisão do governo da "União Nacional" de expulsão de todos os súbditos alemães dos territórios portugueses e de encerramento e confisco dos seus bens e património, ${ }^{12}$ o estabelecimento ainda procurou resistir, durante pouco mais de um ano, com a fusão de classes em turmas mistas e a transferência para instalações mais módicas

\footnotetext{
${ }^{10}$ Vd. Reinhard Biedermann, O Colégio Alemão do Porto: 1901-1991 (Porto: Associação do Colégio Alemão do Porto, 1991).

${ }^{11}$ Vd. Francisco Miguel Araújo, "Aliados versus Inimigos da Nação: sociabilidades no Porto da Grande Guerra", CEM - CEM Cultura, Espaço \& Memória 6 (2015): 145-159.

12 "Decreto n.․․ 2 350, de 20.04.1916", Diário do Governo, I série, 77.
} 
na Boavista. Só que o esforço revelou-se inglório, mesmo contando com um forte contingente português entre a sua população discente, o C.A.P. fechou as suas portas, literalmente de um dia para o outro, após essa confirmação jurídica dos seus administradores e professores como súbditos inimigos.

\section{Colégio Alemão do Porto: intermezzo na Galiza (1916-1919)}

Toda esta questão da proscrição da colónia alemã de Portugal constituiu uma matéria de difícil resolução para as entidades republicanas, entre pedidos de passaportes dos cidadãos alemães e o reconhecimento do título de residência aos que detinham a dupla nacionalidade. A tal ponto da 1. ${ }^{-}$República ter de rever essa legislação e estabelecer situações excecionais para variados segmentos: funcionários públicos do próprio Estado, militares nas forças nacionais e respetivas progenitoras, descendentes até ao $3 .^{\circ}$ grau familiar e os menores de 16 anos que não se pudessem juntar às suas famílias alémfronteiras. ${ }^{13}$

A neutralidade declarada pela Espanha de Afonso XIII em grande parte mitigou este complexo processo, pois este ao autorizar os consulados e representações diplomáticas a conceder vistos para acolher estes expatriados, converteu o reino em principal destino de migração perante o impasse no desenrolar da guerra. No caso dos elementos provindos da cidade do Porto e da zona norte, a província de Pontevedra na Galiza será a preferencialmente eleita como asilo pela sua proximidade geográfica, com muitas famílias a se instalarem nas cidades de Tui e de Vigo.

Nesta última localidade e até ao Armistício de Compiègne, o C.A.P. ressurgirá como uma experiência educativa informal para as crianças alemãs em idade escolar, independentemente da sua frequência prévia, sob a iniciativa do diretor cessante Alexender Geys. Por um lado, porque todo o seu material e património educativo fora leiloado em haste pública pelo Tribunal do Comércio do Porto; ${ }^{14}$ por outro, porque na conjuntura da época seria inexequível reivindicar o seu reconhecimento legal junto dos ministérios alemão e espanhol.

A boa vontade de pais e demais conterrâneos em arrecadar donativos permitiram que se alugassem dois quartos, onde funcionavam as aulas para cinco classes em regime misto e de ensino mútuo, de forma a que os seus percursos escolares não fossem irremediavelmente suspensos. O Prof. Alexender Geys lecionava a maioria das disciplinas dos ensinos primário e secundário, a Prof. ${ }^{\text {a }}$ Auguste Herminie Münch regia o francês, enquanto o inglês era assegurado por uma outra senhora e a física por um engenheiro naval desterrado nesse porto marítimo. Quando um destes professores explicava a matéria de uma das classes, as outras cumpriam em silêncio as tarefas escolares marcadas e prestavam apoio entre si e aos colegas mais novos.

\footnotetext{
13 "Decreto n.․․ 2 377, de 09.05.1916", Diário do Governo, I série, 89.

${ }_{14}$ Processo de arrolamento dos bens do Colégio Alemão do Porto, 1916, Arquivo Nacional da Torre do Tombo, Ministério das Finanças, caixa 528, processo 144.
} 
A verdade é que sobre esta improvisação pragmática do ensino poucos testemunhos nos chegaram, mas será irrefutável a sua importância para que a forma escolar pudesse ser resgatada em poucos anos. A partir de 1919, com o fim das hostilidades bélica e a revogação dos perniciosos decretos, a colónia alemã foi atravessando a fronteira terreste e reavendo as residências familiares e negócios que tinham abandonado em Portugal. De regresso à cidade do Porto, patrocinado pelas famílias Höfle e Burmester, Alexender Geys pôde reunir parte destas classes e continuar a prática letiva em regime de ensino doméstico. Atributos fundamentais para se justificar o restabelecimento da instituição educativa no processo de negociação com a nova República de Weimar (1918-1933).

\section{O Colégio Alemão do Porto: 2. período (1922-1945)}

Saneadas as quezílias político-económicas com a sociedade portuense, gradativamente a comunidade alemã reintegrou-se no seu tecido social, recuperando os anteriores valores demográficos e o dinamismo na economia local do pré-guerra. Passado pouco mais de meio ano da reabertura da Deutsche Schule Lissabon,,$^{15}$ estes membros irão requerer à Legação da Alemanha em Portugal para que também o C.A.P. voltasse à atividade, subsidiado pelo respetivo ministério dos Negócios Estrangeiros e as quotizações dos pais das crianças alemãs, luso-alemãs e até portuguesas que desejavam aí matricular os seus filhos.

A 2 de maio de 1922, depois de alugado um edifício na Foz do Douro e constituída uma nova direção para a "Associação Escolar do Colégio Alemão do Porto" com uma associação complementar de auxílio (Hilfsverein), 36 alunos de diferentes nacionalidades passaram a frequentar as sete classes dos novos ensinos primário e secundário. A estrutura e organização escolar manteve o predecessor modelo, embora entregue a direção ao Prof. Max Schwair, com o ensino em língua alemã, dois professores nacionais recrutados e remunerados no país de origem a e a inclusão de dois docentes portugueses nesse currículo oficial exogéneo.

O contínuo aumento do pedido de inscrições até 1925, sobretudo de portuenses que impôs a criação de um curso extra num idioma do qual não eram autóctones nas primeiras classes da primária (Grundschule), não só ditou a mudança para novas instalações mais amplas e a ampliação do quadro docente, como a revisão do projeto educativo, matizado na aprovação de um novo regulamento interno:

1. O Colégio Alemão do Porto é uma instituição de ensino para crianças alemãs sem distinção de sexo, condição ou religião. Assegura aos seus discípulos uma instrução de acordo com espírito e princípios alemães, utilizando métodos de ensino correntes na Alemanha e prepara os seus alunos para o prosseguimento de estudos ou para o ingresso na vida activa aqui no país.

2. 0 Colégio Alemão encontra-se sob protecção do Reich.

${ }_{15}$ Vd. Joachim Cornelißen \& René Schwerdtfeger, coord., Escola Alemã de Lisboa/ Deutsche Schule Lissabon: 1848-1998 (Lisboa: Vostand des Deutschen Schulvereins. 1998). 
3.- A manutenção do Colégio é assegurada pela comunidade escolar alemã. Esta é composta pelos pais dos alunos e pelos subscritores de uma quota anual. Têm direito a veto os pais e todos os que contribuem com uma quota anual de pelo menos 100 escudos. [...]

17. As propinas trimestrais para as crianças alemãs constam do seguinte: [...]. Para alunos não alemães, as propinas serão acrescidas de $50 \%{ }^{16}$

Já no ano letivo seguinte, a oferta educativa foi alargada até à 10. 돌se (Untersekunda), cujo certificado escolar de "maturidade média" era a habilitação para admissão a cursos superiores técnicos ou a carreiras profissionais semiespecializadas, chamando-se a atenção junto dos responsáveis diplomáticos e ministeriais para a construção de raiz de um edifício escolar próprio, aprovado pela atribuição de um subsídio extraordinário com esse fim. As obras protelaram-se por algum tempo, entre as transmutações políticas internas na passagem para a Ditadura Militar (1926-1933) e a disponibilidade de fundos para 0 ambicioso projeto arquitetónico de dois andares: nove salas de aula, gabinetes de história natural e de física e química, sala de desenho, biblioteca, ginásio, salão de festas e outros espaços administrativos; ${ }^{17}$ que pontualmente seriam partilhados com 0 Orfeão e Club Alemão.

Curiosamente, a escolha do terreno na rua de Guerra Junqueiro para a nova sede do C.A.P. confrontava com o lote em que se erguia a Sinagoga Kadoorie-Mekor Haim, separadas entre si por um simples muro e uma vedação natural, longe ainda de se revelar uma eventual fonte de conflitos até pela ascendência judaica de várias destas famílias luso-alemãs. ${ }^{18} \mathrm{~A}$ sua inauguração oficial, a 15 de março de 1932, satisfez outro desejo antigo de permitir finalmente 0 alargamento ao ensino pré-primário (Kindergarten) que em Portugal tinha pouca expressão:

\begin{abstract}
Menção especial merece o Jardim de Infância, o melhor do Porto. Com instalações modelares, no jardim da infância ensina-se a perfeita realização métodos de Froebel. As crianças aprendem a brincar; vigia-se o seu desenvolvimento intelectual como se vigiam as plantas. Igualmente a brincar, as crianças portuguesas chegam ao convívio com as crianças alemãs e, por processos graduais e sistemáticos, vão-se familiarizando com a língua alemã. Os instrumentos de trabalho são os brinquedos das colecções que o jardim de infância renova constantemente e os trabalhos manuais. Além disso, dispõe de um recreio próprio para ensino ao ar livre. A par do estudo da língua alemã, a sua principal finalidade é criar hábitos de ordem, disciplina e pontualidade no futuro estudante. ${ }^{19}$
\end{abstract}

Uma outra peculiaridade quase imediata, bem mais suspeita pelas suas conotações político-ideológicas, foi a afirmação do III Reich (1933-1945) e o nacionalsocialismo de Adolf Hitler, em sintonia com o Estado Novo de António Oliveira Salazar (1933-1974). Se é certo que na rede de escolas alemãs no estrangeiro houve uma

\footnotetext{
${ }^{16}$ Joachim Heß \& Alfred Haas, coord., Externato Deutsche Schule zu Porto: 100 Jahre/Colégio Alemão do Porto: 100 anos - 1901-2001 (Porto: Associação do Colégio Alemão do Porto, 2001), 35.

${ }^{17}$ Colégio Alemão do Porto: Licença de obra n.. 924/1931, 1931, Arquivo Histórico Municipal do Porto D-CMP/9(606).

${ }^{18}$ Reinhard Schwarz, Os Alemães em Portugal 1933-1945: a colónia alemã através das suas instituições (Porto: Antília Editora, 2006): 163.

${ }^{19}$ Ibídem, 237; transcrição de um folheto promocional que datará de finais da década de 1930.
} 
clara orientação de se limitar a inculcação dos valores nazis na educação das gerações mais novas, em especial a vertente do antissemitismo para evitar adversidades internacionais, somente os estudantes de cidadania alemã eram coagidos a se inscrever na delegação local da Juventude Hitleriana e tomar parte nos eventos festivos e desportivos por ela dinamizados.

Os novos estatutos da Associação Escolar de 1933, todavia, pouco aludem a esta nova realidade ou a tentativas do seu aproveitamento político, de resto, pouco exploradas pelos dois últimos diretores desta fase -Fritz Rübner e Fritz Lichtenberg-, sendo que este último irá demarcar-se por uma postura suficientemente isenta e prudente quanto a outros professores que apregoavam esse ideais vinculados à extrema-direita. ${ }^{20}$ Aliás, recomendável para uma instituição educativa com o duplo rótulo de ensino privado e estrangeiro, em que a representatividade dos alunos portugueses se consolidava e não se deveria afugentar em prol da sua viabilidade económica e funcional.

\section{Gráfico 2. Frequência escolar do C.A.P. ao longo do seu 2.ำ período}

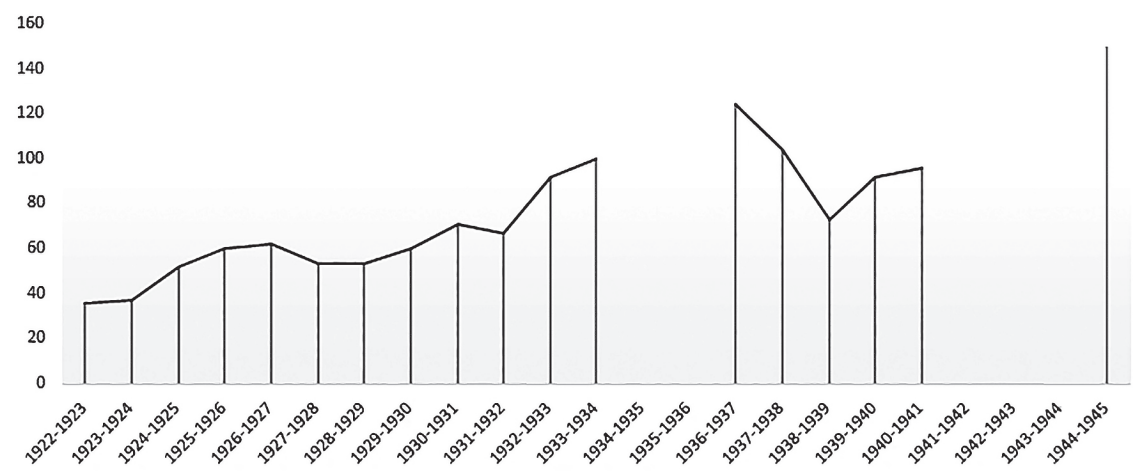

Fonte: Arquivo escolar da Deutsche Schule zu Porto.

As reformulações do projeto pedagógico do C.A.P. assim o vão comprovando: contratação de mais um professor português, reforço do número de horas na disciplina de língua portuguesa, aumento das turmas nos ensinos pré-primário e primário, apoio na preparação para os exames finais nos liceus, etc. Após um primeiro momento de tensão com o irromper da 2. a Guerra Mundial (1939-1945), coincidente com uma quebra nos valores das inscrições, a missão educativa ficou salvaguardada depois de conhecida a neutralidade de Portugal. Perante os cortes no financiamento público para a causa da guerra, estes encarregados de educação irão colmatá-la pelo aumento das propinas trimestrais a pagar.

${ }^{20}$ Araújo, "O Colégio Alemão do Porto (1901-2001)", 117-118. 
Por seu lado, o ministro Mário de Figueiredo ratificou a equivalência dos exames finais no C.A.P. com os do curso geral dos liceus, facilitando a transição destes estudantes para as escolas portuguesas para conclusão do ensino secundário, três anos depois do seu reconhecimento como escola secundária alemã no estrangeiro (instituição não plena), em 25 de abril de 1940, pelo ministro Joachim von Ribbentrop. Contudo, as vicissitudes do conflito armado iam prejudicando cada vez mais o normal funcionamento das atividades letivas, quer pela renúncia e abandono dos docentes estrangeiros, quer pelo aumento de matrículas para a centena e meia de alunos dos quais $2 / 3$ seriam inclusive de origem lusa.

A vitória aliada e desagregação do III Reich no final desse ano letivo de 1944-1945 pelas suas implicações políticas, diplomáticas e económicas determinaram um segundo encerramento do C.A.P., em parte decidido pelos seus administradores, outra pelo confisco dos bens alemães pelo Estado Novo reivindicado pelos países vencedores e demais organismos mundiais. Esta sentença acabaria confirmada, em 1946, ${ }^{21}$ autorizando o ministério da Educação Nacional a continuidade de estudos no ensino particular liceal aos antigos estudantes, depois de validadas as classificações obtidas nas disciplinas comuns com o currículo português.

\section{O Colégio Alemão do Porto: 3.ำ período (1952-...)}

A subsequente indefinição geopolítica da Alemanha até final dos anos de 1940 embargou transitoriamente o futuro do C.A.P., novamente recorrendo-se ao ensino doméstico em pequenos grupos nas casas das famílias Eisele e Burmester-Gloystein, nos quais os professores Alfred Busse e Maria Moitas reuniram as crianças das famílias alemãs que pretendiam um currículo internacional alternativo. A afirmação da soberania da República Federal da Alemanha (R.F.A. - 1949) e o seu interesse particular em reabilitar a rede de escolas alemãs no estrangeiro, afirmando-se internacionalmente em oposição à sua rival comunista da República Democrática Alemã, ${ }^{22}$ alimentou a ideia nascente dos antigos administradores de se voltar a institucionalizar este estabelecimento educativo privativo.

Porém, como o governo da R.F.A. não dispunha então de uma visão estratégica e dos meios financeiros consistentes para este patronato, numa altura em que se constituía a Kultusministerkonferenz (KMK) responsável pelas orientações político-educativas do governo central, o caminho passou pela iniciativa particular com a recolha de fundos entre particulares e empresas, no primeiro semestre de 1952, com respetiva aprovação jurídica dos estatutos da "Sociedade de Instrução e Recreio Deutsche Schule zu Porto". No arranque do ano letivo de 1952-1953, em casa propositadamente alugada na Foz, um total de 20 crianças divididas pelas classes primárias ficaram sob orientação escolar do Prof. Alfred Busse.

\footnotetext{
21 "Decreto-Lei n. 35 825, de 24.08.1946", Diário do Governo, I série, 191.

22 Destaque-se que o Estado Novo, por divergências políticas óbvias, declinou qualquer contato diplomático com a Alemanha Oriental (1949-1990), relações que foram estabelecidas após a revolução democrática de 1974
} 
A 7 de maio de 1953, a Inspeção do Ensino Particular do ministério da Educação Nacional homologava um primeiro alvará de funcionamento do C.A.P. como estabelecimento educativo estrangeiro plenamente enquadrado no sistema português:

Concedido à sociedade de instrução e recreio Deutsche Schule zu Porto alvará de autorização para o funcionamento de um estabelecimento de ensino particular denominado «Externato Deutsche Schule zu Porto, fixando-se a lotação em 48 alunos externos, de ambos os sexos, em regime de planos e programas alemães, sob a direcção de Fernando Moreira. $O$ estabelecimento em referência está situado na Rua de Gondarém, 956, Porto. 0 alvará tem o n. -1292 e a data de hoje..$^{23}$

Em concordância com esta validação oficial, a R.F.A. acedeu aos pedidos para a legitimar provisoriamente como escola alemã, enviando dois professores com a ressalva de se entregar a sua direção a Johann Röehrenbach, de ambos o melhor habilitado academicamente. Um segundo alvará foi, portanto, publicado em substituição e mais detalhado, não só elevando o número máximo de público escolar para um total de 88, como explicitando a oferta educativa aos níveis dos ensinos pré-escolar, primário e $011^{\circ}$ ciclo do ensino liceal, neste caso correspondente à 10. ․ classe do currículo germânico. ${ }^{24} \mathrm{Em} 1956$, a KMK autenticava o C.A.P. como escola alemã no estrangeiro, com direito a conferir o diploma escolar de grau médio (Mittlere Reife), adjudicando uma rubrica especial para a construção de um edifício escolar, visto o antigo ter sido expropriado para a Emissora Nacional de Radiodifusão, voltando-se a escolher a rua de Guerra Junqueiro com encomenda do projeto arquitetónico a Konrad Wiesner e a direção de obra a Arménio Taveira Losa.

Na sua conceção houve um claro cuidado em o adaptar às suas funções e dotá-lo das infraestruturas imprescindíveis para uma capacidade estimada de 340 alunos: salas diferenciadas entre níveis de ensino com rentabilização da luz solar e ventilação natural, aquecimento central, biblioteca, laboratórios, salão de festa, ginásio, piscina, espaços verdes e de lazer decorados com obras de arte e um observatório astronómico em forma de cúpula, que ainda hoje marca aquela paisagem urbana. Na comemoração dos 60 anos da sua fundação, a 9 de outubro de 1961, este espaço foi oficialmente inaugurado pelas autoridades portuenses e alemãs, sendo ainda hoje a sede da instituição após intervenções de expansão e de reabilitação que não o descaracterizaram relativamente ao plano original.

Nas derradeiras décadas do Estado Novo, a cooperação luso-alemã será reforçada em benefício da missão educativa do estabelecimento, com um índice de frequência estudantil em contínuo crescimento exponencial que suplantará o meio milhar de alunos; num ensino em língua alemã e um currículo permeável a algumas necessidades escolares portuguesas, como o idioma e os temas históricos e geográficos, sustentadas pelo Acordo Cultural de 1966 numa maior equiparação entre os dois sistemas educativos. ${ }^{25}$

\footnotetext{
23 "Alvará no. 1 292, de 07.05.1953", Diário do Governo, III série, no. 127.

24 “Alvará no. 1 388, de 20.10.1954", Diário do Governo, III série, no. 262; diploma governamental que se mantém vigente atualmente para efeitos legais, embora naturalmente com reformulações ratificadas por outros documentos legais.

25 "Decreto-Lei n.ำ 46 877, de 18.02.1966", Diário do Governo, III série, 41.
} 


\section{Gráfico 3. Frequência escolar do C.A.P. ao longo do seu 3.ำ período}

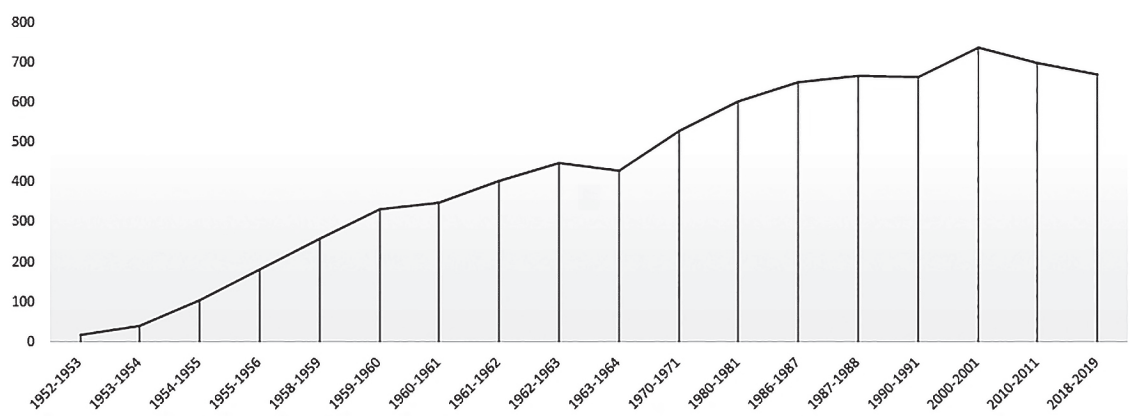

Fonte: Arquivo escolar da Deutsche Schule zu Porto.

No ano seguinte e após solicitação do conselho de administração à KMK, as últimas três classes para a aprovação plena do ensino secundário foram abrangidas e, em junho de 1971, as primeiras alunas finalistas cumpriram esses exames finais (Reifeprüfung ou Abitur) na presença de um seu representante que presidiu ao júri académico. ${ }^{26}$ À distinção de integrar o lote restrito de escolas alemãs no estrangeiro que ofereciam um ensino completo até à entrada no ensino superior, o C.A.P. em 1973 terá sido, supostamente, a primeira instituição particular estrangeira a obter a paridade do seu certificado final com os dos liceus portugueses. ${ }^{27}$

Já depois do 25 de Abril de 1974 e no processo de democratização em Portugal, no qual os seus professores não tiveram papel ativo por recomendação expressa do ministério dos Negócios Estrangeiros da R.F.A., ${ }^{28}$ o C.A.P. pelo seu estatuto de organismo supranacional não foi alvo de qualquer represália e respeitou-se a sua autonomia educativa $e$ administrativa. Aliás, num contexto de verdadeira explosão escolar do sistema educativo português e de definição da sua orgânica e princípios orientadores, promulgada pela "Lei

\footnotetext{
${ }^{26}$ Tendo sido decretada a mobilização militar de todos os portugueses maiores de idade para a Guerra Colonial (1961-1974), em paralelo com este ensino secundário que previa a sua conclusão na 13. a classe, os jovens do género masculino não se inscreviam nesse último ano e transferiam-se para os liceus públicos para finalizar 0 curso complementar. Em caso de sucesso académico e de entrada num curso universitário poderiam, de resto, ser dispensados temporariamente da chamada ao Exército. Deu-se o caso de neste ano letivo nenhum rapaz alemão frequentar esse ano inaugural dos finalistas entre as oito raparigas inscritas no Reifeprüfung.

${ }^{27}$ Este processo em particular parece ter sido outorgado através de pedidos individuais ao ministério da Educação Nacional, para a certificação dos exames e classificações finais emitidas pelo C.A.P. à avaliação ao 7.ำ ano dos liceus, sem publicação de diploma legal para o qual não se encontrou qualquer referência na consulta documental.

${ }^{28} \mathrm{Na}$ agitação revolucionária pré-golpe entre os poucos professores portugueses em exercício também não se afigura nenhum que publicamente se encontrasse ligado aos meios oposicionistas contra o regime de Marcello Caetano. Aos colegas de nacionalidade alemã, em observância à sua qualidade de funcionários públicos da Alemanha Ocidental, era aconselhado não interferirem abertamente na vida política dos seus países de acolhimento.
} 
de Bases do Sistema Educativo" em 1986, a solidez e cosmopolitismo deste projeto pedagógico tornou-o ainda mais apelativo às famílias portuguesas, superando em muito 0 numerus clausus da sua comunidade académica nos anos subsequentes.

Quiçá mais pertinente, neste panorama de políticas educativas e pedagógicas, terán sido antes as mudanças sistémicas resultantes da reunificação da Alemanha (1989-1990) e as consequentes revisões dos programas de financiamento na sua gestão, embora sem alterações de monta no seu modelo de ensino ou no desenho curricular; com a atribuição do título de "Escola de Encontro" (Begegnungsschule). Os seus documentos orientadores até ao presente mantêm a referência a promover um regime de ensino bilingue e intercultural, com reconhecimento dos certificados finais dos graus do ensino primário ao secundário pelos governos alemão e português.

Também as práticas pedagógicas são alvo de frequentes revisões para um melhor enquadramento das necessidades internas e de inovação em prol da proficiência educativa: adoção da avaliação contínua e do ensino diferenciado conforme a língua pátria dos alunos no ensino primário, relevância do ensino pré-escolar, desdobramento de todas as classes para duas turmas cada, introdução das tecnologias digitais, diversificação das atividades extracurriculares ou o regime de paralelismo pedagógico no 1.ำ ciclo do ensino básico, ${ }^{29}$ etc.

No corrente ano de 2019, o C.A.P. permanece como uma escola de referência na cidade do Porto e de toda a zona norte do país, um estudo de caso singular pela sua longevidade centenária, celebrada com pompa e circunstância em 2001, ${ }^{30}$ incorporada na relação das Deutsche Auslandsschularbeit Internationa ${ }^{\beta 1}$ e Weltverband Deutscher Auslandsschu$l e n^{32}$ e agraciada com o selo de qualidade como Exzellente Deutsche Auslandsschule. ${ }^{33}$

\section{0 cosmopolitismo do Colégio Alemão do Porto}

A condição de estabelecimento educativo estrangeiro e particular, tal como noutros exemplos similares, tende a rotular o C.A.P. com um certo elitismo no seu acesso pressuposto pelo número limitado de vagas e o valor anual das propinas, em contraponto com 0 ensino público gratuito. No entanto, pela análise da sua história institucional ao longo dos diferentes períodos em funcionamento, a noção parece se desvirtuar porque nunca se privilegiou um carácter tão hermético face ao meio envolvente, ${ }^{34}$ e justamente 0 seu pendor

\footnotetext{
${ }^{29}$ A ratificação mais recente deste regime foi publicada pelo "Despacho n. ${ }^{0} 6608 / 2000$, de 09.03.2000", Diário da República, II série, 72.

${ }^{30}$ Francisco de Almeida e Sousa, "Os 100 anos do Colégio Alemão do Porto", O Tripeiro, 7. ․ série, XX-11 (2001): 343-344.

${ }^{31}$ Distinção atribuída pela Zentralstelle für das Auslandsschulwesen (ZfA), organismo federal das escolas internacionais regulamentadas segundo o sistema educativo alemão.

${ }^{32}$ Organismo da KMK para representação na associação mundial de escolas alemãs no estrangeiro.

${ }^{33}$ Desde 2008, menção de excelência da qualidade pedagógica enquanto escola no estrangeiro, sujeita a aprovação por inspeção federal alemã, por um período de seis anos.

${ }^{34}$ Em comparação no cenário local, por exemplo, com a Oporto British School, cuja frequência escolar sempre foi bem mais restrita, só ultrapassando a centena de matrículas na $2 .{ }^{\stackrel{a}{a}}$ metade do século XX. E, se na permissão
} 
internacional e intercultural foi sempre uma das maiores valências para que a sociedade portuense a tenha e continue a procurar como território educativo privilegiado.

Transversalmente às suas diferentes fases de funcionamento e vínculos político-ministeriais com os governos da Alemanha no poder, a primazia de um projeto curricular, pedagógico e formativo num sistema de ensino estrangeiro, muito mais cosmopolita e multicultural que compelia a um natural alargar de horizontes intelectuais e cívicos dos seus alunos, pautou-se sempre pela sua adaptação à realidade portuguesa e às exigências quotidianas sentidas na prossecução do processo de ensino-aprendizagem pela sua comunidade escolar. Com esse duplo paradoxo de, em 1909, não só se admitir a matrícula de alunos de outras nacionalidades, mas também em desarticular religião e educação, um laicismo percursor ao aplicado pela 1. ${ }^{-}$República Portuguesa. ${ }^{35}$

Saliente-se, ainda neste sentido, o extenso e sólido processo de oferta educativa de um plano de estudos integral até à atual escolaridade obrigatória portuguesa, consagrado em inícios dos anos de 1970 com a certificação dos exames finais do ensino secundário entre os programas luso-alemães; ou a aposta na obrigatoriedade do ensino pré-escolar como primeira etapa na integração educativa da criança, tão mais relevante em contexto bilingue, uma escolha facultativa no sistema educativo português. Em complemento com uma abrangência curricular e carga horária mais intensas, respeitando os requisitos básicos e tempos individuais na fluência da língua materna e da estrangeira, intercalada com as importantes valências da educação artística, física e cívica no processo de ensinoaprendizagem e a implementação de práticas pedagógicas modernas e diversificadas.

Manifestamente, o fenómeno de internacionalização do C.A.P. encontra-se sempre omnipresente, seja em termos mais burocráticos na sua gestão académica e administrativa, seja pela original constituição de um corpo docente maioritariamente de cidadania alemã, com toda uma formação, sociabilidades e novidades educativas distintas, em constante mobilidade por contratos celebrados a termo certo. Ao ponto de estes poderem ser revogados antes do seu término, mediante parecer do conselho de administração e aplicável independentemente da sua cidadania, quando as suas metodologias e labor profissional não correspondam plenamente ao projeto educativo da instituição.

Ou a promoção do intercâmbio mundial de toda esta comunidade nas muitas atividades desenvolvidas em torno da rede de escolas alemãs no estrangeiro, principalmente a ibérica com o trabalho cooperativo entre os estabelecimentos portugueses e espanhóis em convívios desportivos e culturais anuais, ${ }^{36}$ a concessão de bolsas de estudo e estágios profissionais pela Deutscher Akademischer Austauschdienst (DAAD) e a realização de ações de formação da ZfA. Além do contributo da KMK e de empresas alemãs na doação

para rapazes de outras nacionalidades a antecedeu, logo em 1902, a entrada do género feminino de qualquer cidadania tardou por mais doze anos.

${ }^{35}$ Vd. Joaquim Pintassilgo, coord., Laicidade, Religiões e Educação na Europa do Sul no século XX (Lisboa: Instituto de Educação da U.Lisboa, 2013).

${ }^{36} \mathrm{Vd}$. Dominik Herzner, Deutsche Auslandsschulen in Spanien: Auswärtige Kulturpolitik zwischen Kinflikt und Kooperation (Bielefeld: Transcript, 2019). 
de material didático, de equipamentos informáticos, de instrumentos musicais, de comparticipação nas obras de requalificação, entre outros.

Talvez o paradigma que melhor poderá ilustrar este corolário da sua administração e política educacional seja a obediência à livre elegibilidade dos futuros alunos, na qual a cidadania alemã não é considerada um direito jurídico no seu acesso, que em caso de não se ajustarem aos critérios linguísticos, curriculares e didáticos, num processo de avaliação contínua e de apoio extracurricular, são aconselhados a explorar outros modelos educativos. No final dos seus percursos académicos, os alunos do C.A.P. realçam, de forma quase unânime, o clima familiar e multicultural em que cresceram e uma educação integral assente em valores como os da disciplina, sentido crítico, flexibilidade e cultura intelectual preconizadas para a sua inclusão num mundo globalizado.

Uma característica que historicamente sempre foi um forte fator de atração para as famílias portuguesas, desde os tempos do republicanismo e até nos do autoritarismo, cientes de que os seus educandos aqui teriam uma maior consciência das realidades supranacionais. Inclusive, alguns antigos alunos durante o Estado Novo recordam que a opção das famílias por esta escola não foi inocente, salvaguardado por um currículo internacional autónomo e uma proposta educativa bilingue e especializada, equacionada como um trunfo para as suas qualificações pessoais e profissionais. Era comummente sabido que certas matérias consideradas sensíveis e relegadas do ensino português eram aqui abordadas com maior liberdade, nomeadamente assuntos de geopolítica e história mundial, despertando a consciência para o atraso estrutural do regime e as estratégias para a sua subsequente modernização, democratização e europeização, perseveradas após a adesão à Comunidade Económica Europeia/União Europeia desde 1986.

Será esta pertinência de um cosmopolitismo e de modernidade educativa do C.A.P., conciliando as exigências oficiais do sistema educativo alemão com as expetativas pessoais de pais e alunos, que a justificam como escola de referência estrangeira e intercultural no subsistema do ensino particular em Portugal. Pela qualidade de um ensino definido pelo desenvolvimento da autonomia, liberdade e criatividade do aluno nas suas diferentes dimensões formativas, duplamente reconhecido pelos ministérios dos dois países, e cujas dinâmicas estruturantes não deixaram de se imiscuir para a renovação pedagógica do próprio sistema educativo português.

\section{A portugalidade do Colégio Alemão do Porto}

A aculturação às qualidades ou a um certo sentido de Portugal e dos portugueses emerge em todos os capítulos da história institucional do C.A.P., algo a que uma escola estrangeira poderia mostrar naturais resistências, como um dos atributos peculiares na construção de uma verdadeira identidade luso-alemã. Mas, jamais deixou-se de estimular a aproximação e inserção do seu projeto socioeducativo na sociedade portuense, num clima de abertura, tolerância e respeito mútuo, aquiescendo não só às expetativas da colónia alemã como às da população portuguesa em geral. 
Mesmo sendo as suas instalações um centro nevrálgico para as atividades dos organismos alemães na cidade do Porto ou da sua direção escolar por imperativos legais ser confiada unicamente a estes concidadãos, em todas as festividades solenes, académicas, desportivas e lúdicas dinamizadas os convites continuam a estender-se a toda a comunidade. E, do mesmo modo que se celebram os grandes feriados nacionais da Alemanha, também as efemeridades portuguesas sempre foram aqui comemoradas, tanto nacionais como locais, com destaque para a grande festa popular do S. João. Prova de que o patriotismo e nacionalismo alemães não estariam profundamente arreigados a uma postura proselitista ou altiva da língua, cultura e tradições do país de origem; de resto, legitimado pela assimilação social destas linhagens por via de casamento com conjugues portugueses e perpetuado pelas gerações familiares que se lhes seguiram.

Em termos educacionais uma portugalidade que se refletiu em várias situações ao longo das décadas, algumas das quais dignas de nota pela sua originalidade e pragmatismo que se encontram na sua génese. A contratação de professores portugueses desde 1910, quer para o ensino da língua portuguesa como a primeira das línguas estrangeiras, ${ }^{37}$ quer das disciplinas de história, geografia e literatura portuguesas para uma coexistência intercultural e a eventual transição entre ambos os sistemas educativos na apresentação aos exames oficiais. Já em 1927, a adoção do calendário escolar português de outubro a julho, uma estratégia eficaz para congregar um maior número de matrículas deste segmento estudantil, minorando as taxas de absentismo e os inconvenientes na gestão do tempo em família.

A preocupação na criação de turmas restritas entre as várias classes aos alunos portugueses, pelo menos regulamentado a partir de 1925, coadjuvando a sua fluência linguística pelo reforço do número de horas semanais que lhe era dedicado; igualmente aplicado, em sentido inverso, aos colegas estrangeiros para dominarem o idioma em que se desenrolavam as suas vivências fora deste espaço educativo. Em finais dos anos 30 , numa altura em que o material didático alemão não contemplava os estudos de regiões além-fronteiras, parte integrante do currículo no ensino primário, a direção prescindiu da carga letiva na análise de um dos estados alemães em favor deste ensino das línguas vivas; disposição que depois será revista na sua segunda reabertura, com a inclusão de temáticas etnográficas sobre Portugal, a região norte e a cidade do Porto nos projetos pedagógicos e atividades extracurriculares implementadas.

E se a doutrinação ideológica foi evidente durante a vigência do nacional-socialismo de Hitler, pela ação do posto da Juventude Hitleriana em festas solenes, competições desportivas e palestras para o conjunto alemão, mais duradoura foi a observância a um papel similar promovido pelo Estado Novo de Salazar na educação portuguesa: a omnipresença

\footnotetext{
${ }^{37}$ Em 1937, numa circular oficial do III Reich, o inglês será escolhido como segunda língua estrangeira para a rede educativa das suas escolas no estrangeiro, dando a precedência ao idioma do país de acolhimento. Enquanto que nos estabelecimentos portugueses, aproximadamente até meados dos anos de 1980, o francês era preferencialmente a primeira língua estrangeira lecionada e o alemão quase sempre foi uma residual opção de escolha entre os alunos.
} 
dos retratos do presidente da República e do Conselho de Ministros no hall de entrada, a delegação da Mocidade Portuguesa, a reorganização curricular do então ensino liceal entre os ramos complementares das ciências e das letras ou a breve experiência do ensino diferenciado entre géneros nas classes primárias.

Ainda que a inculcação destes valores nacionalistas tenha sido atenuada gradualmente com a passagem à supervisão pela R.F.A. e uma consequente política educativa de pendor demoliberal, com uma gradual e precoce equivalência das habilitações académicas entre os graus de ensino, com a qual Portugal se acaba por correlacionar no retorno à sua própria democratização e europeização, mas agora também no fenómeno de globalização. Por exemplo, com o aparente mérito, em 1973, de ter sido a primeira escola estrangeira certificada em Portugal em todos os ciclos da sua oferta educativa; passado um ano com o pedido às autoridades ministeriais de redução de um ano no ensino secundário, para se adaptar à realidade portuguesa de doze anos de escolaridade, num regime de autonomia pedagógica que mantém o beneplácito da KMK e a recognição da sua excelência educativa.

Por último, o excecional contributo do C.A.P. para o panorama cultural, científico e educativo portuense, seja pelos concertos musicais, as representações teatrais, as investigações no observatório astronómico, seja pelas palestras e conferências com preletores portugueses e estrangeiros ou a oferta complementar de cursos de alemão e de português, alguns dos quais em articulação com a Universidade do Porto e o Goethe-Institut. Na ausência da Faculdade de Letras do Porto, entre 1931 e 1961, agravada com a lacuna da seção de Filologia Germânica até 1972, foram estes professores que, através da "Sala de Cultura Alemã"/ "Instituto de Cultura Alemã", ${ }^{38}$ prestaram a sua colaboração na divulgação da língua e culturas alemãs nesse espaço universitário.

Assim, estabelecendo-se a cooperação e as sinergias internacionais para uma convergência das finalidades educativas, mais notória nas últimas décadas do século $X X$, com esse objetivo de dotar o estabelecimento com um fidedigno projeto pedagógico lusoalemão.

\section{Notas finais}

Não abundam em Portugal as instituições educativas com mais de um século e que continuam em funcionamento com uma dinâmica escolar, pedagógica e inovadora assaz homogéneas, mesmo que com ruturas pontuais e transmutações das políticas educativas, como neste caso particular da Deutsche Schule zu Porto. Tão mais surpreendente enquanto estabelecimento do ensino particular e cooperativo e de escola alemã no estrangeiro, uma nação com a qual as afinidades históricas e culturais até nem seriam tão acentuadas, em comparação com a diplomacia portuguesa junto de outros países europeus.

\footnotetext{
${ }^{38}$ Francisco Miguel Araújo, «The University of Porto in the path of European Science: innovations, exchanges and resistances during World War II», Debater a Europa, no. 13 (2015): 119-141.
} 
E, no entanto, este espaço escolar foi e é cenário para uma alternativa ao sistema educativo oficial português, daquilo que hoje se pode concetualizar como uma educação liberal, contrariando até a imagem da mentalidade formal, economicista e disciplinadora que muitas famílias portuenses tendem a ter do povo alemão. Uma maior liberdade de ensino, a aposta numa formação integral e intercultural, o estímulo da capacidade crítica, o pleno desenvolvimento pessoal em todas as suas dimensões, sustentado por uma educação bilingue, as pedagogias e didáticas ativas, as novas tecnologias de informação e comunicação e as estratégias diferenciadoras de ensino em função das línguas mães e de um processo de avaliação contínua, etc. A um ritmo bem mais célere do que as escolas portuguesas puderam oferecer neste mesmo arco cronológico, como o domínio fluente de uma língua estrangeira e um currículo diversificado e internacional, o que legitima a quase hegemonia do público escolar português na sua frequência, superior a $80 \%$ do seu total em inícios deste século XXI.

Um paradigma sob os princípios da equidade, modernidade, diversidade, tolerância e interculturalidade, que the conferem esse genuíno significado de Begegnungsschule e que tem sabido retorquir aos desafios suis generis de modernidade, cosmopolitismo e portugalidade que a Educação Ihe vai lançando:

Esta é também uma forma de exprimir o agradecimento devido a todos aqueles que fizeram desta escola a instituição que hoje somos: um estabelecimento de ensino aberto ao mundo e orientado para o futuro, uma ponte entre as culturas alemã e portuguesa, um local de estudo e aprendizagem que, como núcleo de um longo e profundo entendimento entre alemães e portugueses, procura estreitar de variadas formas a amizade entre os dois povos, tendo construído um nome amplamente respeitado e gozando de grande reconhecimento por parte de portugueses e alemães. ${ }^{39}$

\section{Bibliografia}

Almeida e Sousa, Francisco de. "Os 100 anos do Colégio Alemão do Porto", 0 Tripeiro, 7. a série, XX-11 (2001): 343-344.

Araújo, Francisco Miguel. "Aliados versus Inimigos da Nação: sociabilidades no Porto da Grande Guerra", CEM - CEM Cultura, Espaço \& Memória 6 (2015): 145-159.

Araújo, Francisco Miguel. "O Colégio Alemão do Porto (1901-2001): um processo de inovação pedagógica a três tempos", em Roteiros da Inovação Pedagógica: Escolas e experiências de referência em Portugal no século XX / Itineraries of pedagogical innovation: reference schools and experiences in Portugal in the twentieth century, coord. Joaquim Pintassilgo \& Luís Alberto Marques Alves, 103-136. Lisboa: Instituto de Educação da Universidade de Lisboa, 2019.

Araújo, Francisco Miguel. "The University of Porto in the path of European Science: innovations, exchanges and resistances during World War II", Debater a Europa 13 (2015): 119-141.

${ }^{39}$ Joachim Heß \& Alfred Haas, Externato Deutsche Schule zu Porto, 9. 
Barros, Amândio. "Nas origens de uma respublica marítima e mercantil: o acolhimento ao estrangeiro nos portos medievais e modernos," CEM - CEM Cultura, Espaço \& Memória 6 (2015): 45.

Cornelißen, Joachim \& Schwerdtfeger, René coord., 1998. Escola Alemã de Lisboa/ Deutsche Schule Lissabon: 1848-1998. Lisboa: Vostand des Deutschen Schulvereins.

Direcção-Geral da Estatística, Censo da População de Portugal no 1. de Dezembro de 1911: V recenseamento geral da população (Lisboa: Imprensa Nacional, 1913).

Herzner, Dominik. Deutsche Auslandsschulen in Spanien: Auswärtige Kulturpolitik zwischen Kinflikt und Kooperation (Bielefeld: Transcript, 2019).

Joachim Heß, Joachim \& Alfred Haas, Alfred, coord., 2001. Externato Deutsche Schule zu Porto: 100 Jahre/Colégio Alemão do Porto: 100 anos - 1901-2001. Porto: Associação do Colégio Alemão do Porto.

Oliveira Ramos, Luís de, coord., 2015. História do Porto. Porto: Porto Editora.

Pintassilgo, Joaquim, coord., 2013. Laicidade, Religiões e Educação na Europa do Sul no século XX. Lisboa: Instituto de Educação da U.Lisboa.

Reinhard Biedermann, Reinhard. O Colégio Alemão do Porto: 1901-1991. Porto: Associação do Colégio Alemão do Porto, 1991.

Reinhard Schwarz, Reinhard. Os Alemães em Portugal 1933-1945: a colónia alemã através das suas instituições. Porto: Antília Editora, 2006.

\section{Fontes documentais}

"Alvará 1 292, de 07.05.1953", Diário do Governo, III série, 127.

"Alvará 1 388, de 20.10.1954", Diário do Governo, III série, 262.

“Decreto 2 350, de 20.04.1916”, Diário do Governo, I série, 77.

“Decreto 2 377, de 09.05.1916”, Diário do Governo, I série, 89.

"Decreto-Lei 35 825, de 24.08.1946", Diário do Governo, I série, 191.

"Decreto-Lei 46 877, de 18.02.1966", Diário do Governo, III série, 41.

"Despacho 6608/2000, de 09.03.2000", Diário da República, II série, 72.

Licença de obra 924/1931, 1931, Arquivo Histórico Municipal do Porto, D-CMP/9(606).

Processo de arrolamento dos bens do Colégio Alemão do Porto, 1916, Arquivo Nacional da Torre do Tombo, Ministério das Finanças, caixa 528, processo 144. 